\section{Conclusions}

Clinicians and those involved in service development sometimes dismiss academic research because of an "ivory tower" approach that pays too little attention to issues around service delivery. ${ }^{22}$ The nature of negotiated access to research subjects in primary care settings can have a direct effect not only on participation rates in research but also on the quality of the research data. ${ }^{23}$ If a trial is to be executed successfully, and its findings are to be applicable in a service setting, it is important to identify a trial design that can best reconcile the interests of research, development, and practice. Our analytical framework provides an approach by which it is possible to explore how particular characteristics of trial design appear from each perspective and thereby to assess the most satisfactory design options. The approach cannot assure that trial design will be straightforward and problem free, but early consideration of the perspectives of research, development, and practice might help to prevent fundamental problems arising later.

The study was carried out in collaboration with the MRC General Practice Research Framework, and we are grateful to participating practice staff and Dr M Vickers.

Contributors: AH and IN had the original idea for a trial. SR was overall coordinator of both design and execution of the exploratory trial, organised recruitment of the study practices, and developed packs of evidence based guidelines. $\mathrm{CH}$ and ZT designed and executed the qualitative component of the study. IN and SL developed and implemented the intervention strategies used in the feasibility study. SR, C Hill, and S Goubet developed the quantitative outcome measures. The steering group for the study comprised the authors, S Goubet, and C Hill. L Klinger, J Hickling, and M Griffin assisted with collection, checking, or analysis of data. Advisors to the project included M Vickers, M Lawrence, S Thompson, P Greenhalgh, S Ebrahim, and J Roberts. M Modell, R Morris, and D Mant (who was an external reviewer) gave valuable comments on earlier drafts of this paper. SR is the guarantor for the paper.

Funding: NHS Research and Development Implementation Methods Programme.

Competing interests: None declared.

1 Oxman AD, Thomson MA, Davis DA, Haynes RB. No magic bullets: a systematic review of 102 trials of interventions to improve professional practice. Can Med Assoc J 1995;153:1423-31.
2 Effective Health Care. Getting evidence into practice. York: University of York, 1999.

3 Lawrence M, Packwood T. Adapting total quality management for general practice: evaluation of a programme. Qual Health Care 1996;5:151-8.

4 Hearnshaw H, Reddish S, Carlyle D, Baker R, Robertson N. Introducing a quality improvement programme to primary healthcare teams. Qual Health Care 1998;7:200-8.

5 Wyatt JC, Paterson-Brown S, Johanson R, Altman DG, Bradburn MJ, Fisk NM. Randomised trial of educational visits to enhance use of systematic reviews in 25 obstetric units. BMJ 1998:317:1041-6.

6 Solberg LI, Kottke TE, Brekke ML. Will primary care clinics organise themselves to improve the delivery of preventive services? A randomised controlled trial. Preventive Med 1998;27:623-31.

7 Goldberg HI, Wagner EH, Fihn SD, Martin DP, Horowitz CR, Christensen $\mathrm{DB}$, et al. A randomized controlled trial of CQI teams and academic detailing: can they alter compliance with guidelines. Jt Comm J Qual Improw 1998:24:130-42

8 Shortell SM, Bennett CL, Byck GR. Assessing the impact of continuous quality improvement on clinical practice: what will it take to accelerate progress? Milbank Quarterly 1998;76:593-624.

9 Cochran and Cox. Experimental designs. New York: Wiley, 1957.

10 Altman DG. Practical statistics for medical research. London: Chapman and Hall, 1991.

11 Medical Research Council General Practice Research Framework. A network of general practices throughout the UK managed by the MRC Epidemiology and Medical Care Unit. London: EMCU, Wolfson Institute of Preventive Medicine, 1997.

12 Neufield VR, Woodward CA, McLeod SM. The McMasters MD programme: a case study in renewal in medical education. Acad Med 1989;64:423-32.

13 Berwick D. A primer on the improvement of systems. BMJ 1996;312:61922.

14 Tomlin Z, Humphrey C, Rogers S. General practitioners' perceptions of effective health care. BMJ 1999;318:1532-5.

15 Stephens R, Gibson D. The impact of clinical trials on the treatment of lung cancer. Clin Oncol 1993;5:211-9.

16 Brewin CR, Bradley C. Patient preferences and randomised clinical trials. BMJ 1989;299:313-5

17 Anderson NR, West MA. The team climate inventory:manual and users guide Windsor: Assessment Services for Employment/National Foundation for Educational Research-Nelson Press, 1994.

18 Pritchard P, Pritchard J. Teamwork for primary and shared care. Oxford: Oxford University Press, 1994.

19 Sibley J, Sackett DL, Neufeld V, Gerrard B, Rudnick KV, Fraser W. A randomized trial of continuing medical education. $N$ Engl J Med 1982;306:511-5.

20 Bradley F, Wiles R, Kinmonth A-L, Mant D, Gantley M. Development and evaluation of complex interventions in health services research: case study of the Southampton heart integrated care project. $B M J$ 1999;318:711-5

21 Schwarz D, Lellouch J. Explanatory and pragmatic attitudes in therapeutic trials. J Chronic Dis 1967;20:637-48.

22 Dawson S. Inhabiting different worlds: how can research relate to practice? Qual Health Care 1997;6:177-8.

23 Murphy E, Spiegal N, Kinmonth AL. "Will you help me with my research?" Gaining access to primary care settings and subjects. Br J Gen Pract 1992;42:162-5.

(Accepted 14 April 2000)

\title{
Use of statins in general practices, 1996-8: cross sectional study
}

\author{
C Packham, J Pearson, J Robinson, D Gray
}

The rationale for prescribing statins is well established. ${ }^{1}$ Recently there has been an increase in the rate of prescribing of lipid lowering drugs, although large variations remain between practices. ${ }^{2}$ Fewer prescriptions are written in practices in more deprived areas; ; is not clear what effect local guidelines have on such inequalities. The aim of this study was to describe changes in the rate of prescribing statins between general practices after the introduction of national and local guidelines.

\section{Methods and results}

The study population included 110 of 118 general practices in Nottingham. The main reason for excluding practices was poor quality data. Townsend scores, which measure deprivation on a scale of 4.8 (most deprived) to -3.6 (least deprived), ${ }^{4}$ were derived for practices using the weighted sum of census information from enumeration districts for patients registered with each practice. Data from prescribing and cost reports were collected over three six-month periods from 1 April to 30 September in 1996, 1997, and 1998. Average daily quantities were used to determine the daily dose of statins prescribed and were expressed as a rate (statin-years) of prescribing per 1000 patients aged 35-69. Variables were logarithmically transformed; multiple linear regression was used to examine the relation between prescribing and deprivation by adjusting for list size,
Correspondence to: C Packham chris.packham@ nottingham.ac.uk

continued over

BMJ 2000;320:1583-4 
Divisions of Public Health Medicine and Epidemiology, University Hospital Queen's Medical Centre, Nottingham NG7 2UH

C Packham consultant senior lecturer

J Pearson

senior lecturer in medical statistics

Division of

Cardiovascular Medicine,

University Hospital

Queen's Medical

Centre

D Gray

reader in medicine

Nottingham Health

Authority,

Nottingham

NG1 6GN

J Robinson

epidemiologist

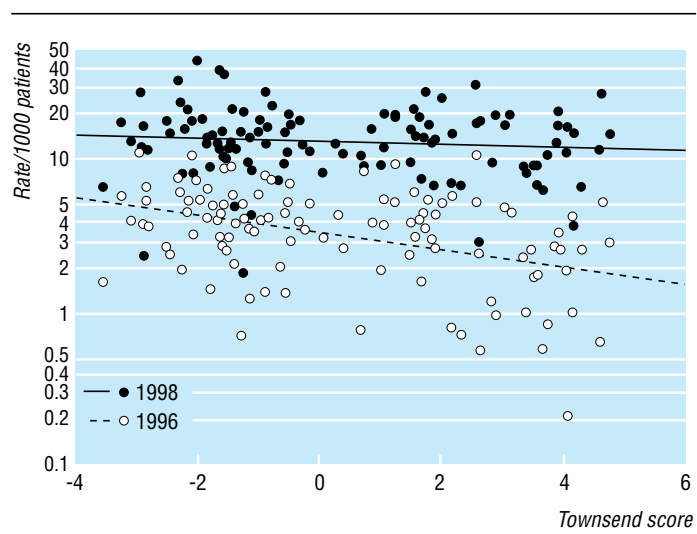

Relation between Townsend score of each practice and rate of statin prescribing per 1000 patients aged 35-69 in 1996 and 1998. Regression lines show unadjusted analyses

practice status (training or fundholding or both), the number of general practitioners, total admissions standardised for age, rates of admissions and outpatient referrals, and the cost of all cardiovascular drugs excluding lipid lowering drugs.

During 1996, the rates of prescribing statins varied from a median of 3.8 statin-years per 1000 adults overall and a median of 4.9 in the quintile of practices classed as least deprived to a median of 2.0 in the quintile classed as most deprived. These rates increased in 1998 to a median of 13.2 statin-years among all practices and to a median of 15.3 in the least deprived quintile and 10.8 in the most deprived. In each year practices in the most deprived areas had lower rates of prescribing than those in more affluent areas.

In 1996 there was a significant inverse relation between deprivation and rates of prescribing statins, with the Townsend score explaining $14 \%$ of the variation after adjustment for the costs of cardiovascular drugs and practice population aged 35-69 years $(\mathrm{P}<0.0005)$. In 1997 and 1998, proportionally larger increases in prescribing occurred among practices in more deprived areas; no significant relation between deprivation and prescribing rates was found during this time. Using Townsend scores of +3 and -3 to represent practices in deprived and more affluent areas, we found a $63 \%$ greater increase in prescribing statins among practices in deprived areas compared with those in more affluent areas between 1996 and 1997 and an 88\% greater increase between 1997 and 1998 (figure).

\section{Comment}

The prescription of statins in primary care in Nottingham increased fourfold between 1996 and 1998; the greatest increase occurred in the most deprived areas. The data precluded assessment of the needs of individual patients. ${ }^{5}$ It is possible that patients in practices in deprived areas and patients in more affluent areas differed in their access to medical care, resulting in a lower level of prescribing in more deprived practices. The appropriateness of prescribing was not assessed; local guidelines on statins focused mainly on secondary prevention but we were not able to assess whether the reduction in the difference between the practices was due to the use of statins in secondary prevention.

We do not know whether the observed pattern of prescribing will change or whether the use of statins by practices in more deprived areas will continue to increase at different rates depending on the level of deprivation. A more detailed study is warranted to establish whether changes in prescribing were the result of the introduction of new guidelines in late 1996, increasing familiarity with statins, or an improved awareness of statins among practitioners in the most deprived areas.

We would like to thank Nicola Alexander, pharmacy support officer, and Dr Sarah Wilson, director of public health, Nottingham Health Authority, for their help in preparing this work.

Contributors: CP developed the idea for this paper in discussion with JR. The data were collected by JR and CP with help from health authority staff. Data were analysed by JP with contributions from CP, DG, and JR. All authors contributed to writing the paper. JP is guarantor for the study.

Funding: None.

Competing interests: None declared.

1 Scandinavian Simvastatin Survival Study Group. Randomised trial of cholesterol lowering in 4444 patients with coronary heart disease: the Scandinavian simvastatin survival study (4S). Lancet 1994;344:1383-9.

2 Baxter C, Jones R, Corr L. Time trend analysis and variations in prescribing lipid lowering drugs in general practice. BMJ 1998;317:134-5.

3 Packham C, Robinson J, Morris J, Richards C, Marks P, Gray D. Statin prescribing in Nottingham general practices: a cross-sectional study. J Public Health Med 1999;21:60-4.

4 Townsend P, Phillmore P, Beattie A. Health and deprivation:inequality in the north. London: Croom Helm, 1988.

5 Picken DM, Payne JN, Haq IU, McCabe CJ, Ward SE, Jackson PR, et al. Statin therapy/HMG Co-A reductase inhibitor treatment in the prevention of coronary heart disease: guidance notes for purchasers 96/04. Sheffield: University of Sheffield, 1996

(Accepted 3 February 2000)

\section{Email submissions from outside the United Kingdom}

We are now offering an email submission service for authors from outside the UK. The address is papers@bmj.com

Ideally our email server would link seamlessly with our manuscript tracking system, but for now it does not, which is why we are offering the service only to authors outside the UK. Most post in the UK arrives the next day, so UK authors have the least to gain in speed of delivery from email delivery. As soon as our systems improve we will invite email submissions from everyone.

If you choose to send your submission by email please would you send the text and any tables and figures as attached files, together with a covering letter giving all your contact details (postal address, phone, fax, and email address). We can read files created with most word processing, graphics, and spreadsheet programs.

When your submission is received in our email box you will receive an automatic acknowledgment to show that it has arrived. If the submission is incomplete we will contact you and ask you to resend the missing information.

Once the submission is complete we will register it on our manuscript tracking system and you will receive a standard acknowledgment in the post.

Letters to the editor should continue to be sent direct to bmj.com as rapid responsesor toletters@bmj.com

papers@bmj.com 